\title{
Quick synthesis of a novel combinatorial delivery system of siRNA and doxorubicin for a synergistic anticancer effect
}

This article was published in the following Dove Press journal: International Journal of Nanomedicine

\author{
Mengchun Chen ${ }^{1,2}$ \\ Ledan Wang' \\ Fang Wang ${ }^{\prime}$ \\ Fan $\mathrm{Li}^{3}$ \\ Weiliang $\mathrm{Xia}^{3}$ \\ Hongchen $\mathrm{Gu}^{3}$ \\ Yijie Chen'
}

'Department of Obstetrics and Gynecology, The Second Affiliated

Hospital and Yuying Children's Hospital of Wenzhou Medical University,

Wenzhou 325027, People's Republic of China; ${ }^{2}$ Department of Pharmacy, The Second Affiliated Hospital and Yuying Children's Hospital of Wenzhou Medical University, Wenzhou, Zhejiang 325000, People's Republic of China; ${ }^{3}$ State Key Laboratory of Oncogenes and Related Genes, School of Biomedical Engineering, Shanghai Jiao Tong University, Shanghai 200032, People's Republic of China
Correspondence: Hongchen Gu Med-X Research Institute, Shanghai Jiao Tong University, 1954 Huashan Road, Shanghai 200032, People's Republic of China

Tel +862162932904

Fax +862162932907

Email hcgu@sjtu.edu.cn

Yijie Chen

Department of Obstetrics and

Gynecology, The Second Affiliated Hospital and Yuying Children's Hospital of

Wenzhou Medical University, 109 West

Xueyuan Road, Wenzhou, Zhejiang

325000 , People's Republic of China

Tel +865 7788002815

Email chenyijie@wmu.edu.cn
Purpose: Combining siRNA and other chemotherapeutic agents into one nanocarrier can overcome the multidrug resistance (MDR) phenomenon by synergistically MDR relative genes silencing and elevated chemotherapeutic activity. Most of these systems are typically fabricated through complicated procedures, which involves materials preparation, drug loading and modifications. Herein, the purpose of this study is to develop a new and fast co-delivery system of siRNA and doxorubicin for potentially synergistic cancer treatment.

Methods: The co-delivery system is constructed conveniently by a stable complex consisting of doxorubicin bound to siRNA via intercalation firstly, followed by interacting with (3Aminopropyl)triethoxysilane (APTES) electrostatically and Tetraethyl orthosilicate (TEOS) co-condensed, and the characterizations of the resultant nanocarrier are also investigated. Furthermore, this study evaluates the synergistic anti-cancer efficacy in MCF-7/MDR cells after treatment of siRNA and doxorubicin 'two in one' nanocarriers.

Results: We establish a new and fast method to craft a co-delivery system of siRNA and doxorubicin with controllable and nearly uniform size, and the entire fabrication process only costs in about 10 minutes. The resultant co-delivery system presents high loading capacities of siRNA and doxorubicin, and the encapsulated doxorubicin plays a $\mathrm{pH}$-responsive control release. Further, biological functionality tests of the synthesized co-delivery nanocarriers show high inhibition of P-gp protein encoded by MDR-1 gene in MCF-7/MDR cells (a variant of human breast cancer cell line with drug resistance) after transfection of these nanocarriers carrying MDR-1 siRNA and doxorubicin simultaneously, which sensitize the MCF-7/MDR cells to doxorubicin, overall leading to improved cell suppression.

Conclusion: Collectively, this co-delivery system not only serves as potent therapeutics for synergistic cancer therapy, it also may facilitate the bench-to-bedside translation of combinatorial delivery system as a robust drug nanocarrier by allowing for fabricating a simply and fast nanocarrier for co-delivery of siRNA and doxorubicin with predictable high production rate. Keywords: siRNA, doxorubicin, codelivery system, multidrug resistance, cancer therapy

\section{Introduction}

One of the major obstacles for effective cancer chemotherapy is the development of drug resistance pathway(s) in cancers, ${ }^{1,2}$ which is commonly associated with cancer cell's overexpression of drug transporter proteins such as P-glycoprotein (P-gp) $)^{3,4}$ that pump out many conventional chemotherapeutic agents from cells, ultimately resulting in treatment failure in most cancers. ${ }^{1,2}$ As chemotherapy remains the dominant approach to cancer treatment, it is imperative to develop cancer treatment strategies that address drug resistance, an area where siRNA has shown potential. ${ }^{5,6}$ siRNA as 
therapeutics could be tailored to the treatment of various diseases of interest, including cancer, by inducing potent, lasting silencing of a broad range of genetic targets critical for cancer development. $^{7-9}$ These siRNA-based therapeutics are considered favorable supplements to chemotherapeutics. However, our previous work $^{8,10}$ had demonstrated that siRNA as therapeutics alone could not eliminate a significantly greater number of resistant cancer cells, such as cancer stem cells, ${ }^{11}$ suggesting that a therapeutic strategy incorporating other anticancer drugs or that synergizes with other anticancer mechanisms should be considered.

In this regard, researchers sought to develop a number of nanoparticle-based co-delivery platforms that ferry siRNA simultaneously with doxorubicin (a classical anticancer drug) to cancer cells for more effective cancer inhibition. ${ }^{4,12,13}$ Most of these co-delivery systems were constructed from several key components: a mesoporous silica nanoparticles (MSNs) core with encapsulated doxorubicin, a cationic poly-macromolecules capped for the siRNA binding and/or following modifications. These vectors successfully enhanced chemotherapeutic cytotoxicity by the assistance of siRNA in drug-resistant cancers, yet this preparatory method is more complicated and time-consuming. Recently, researchers reported a proof-of-principle test of the use of a combined doxorubicin-double stranded nucleotide (such as plasmid, ${ }^{14,15}$ or aptamer ${ }^{16,17}$ ) complex to promote the chemotherapy efficacy. Thus, the above results provided us with clues to engineer smart siRNA-doxorubicin complex-based nanocarrier for applications to cancer therapy.

In the current study, we establish a new and efficient method for constructing a nanocarrier for the co-delivery of siRNA-doxorubicin to treat cancer. As shown in Figure 1A, the doxorubicin first intercalates into the double-stranded region of siRNA to form a physical complex, denoted as siRNA-doxorubicin complex. Then, the achieved siRNA-doxorubicin complex may be used as novel anionic surfactants for development of siRNA-doxorubicin-based silica nanoparticles (denoted as siRNA-doxorubicin- $\mathrm{SiO}_{2}$ ) mediated by (3-aminopropyl)triethoxysilane (APTES) (a type of co-structure-directing agent (CSDA)) and co-condensed by tetraethyl orthosilicate (TEOS) (a type of silicon source), of which the method is inspired from previously published works. ${ }^{18-21}$ The whole preparatory process could be completed conveniently in about 10 mins without the preparation of inorganic materials beforehand nor drug encapsulation procedure. Consequently, this co-delivery system could enhance the sensitivity of MCF-
7/MDR cells to doxorubicin by the assistance of MDR-1 siRNA's interference after transfecting MDR-1 siRNA-doxorubicin- $\mathrm{SiO}_{2}$ nanocarrier, overall leading to elevated cytotoxicity as a result of overcome drug-resistance.

\section{Materials and methods}

\section{Reagents}

APTES and TEOS were purchased from Sigma-Aldrich (Germany). Cell counting kit-8 (CCK-8) was obtained from Sigma Aldrich (USA). Hoechst 33,342, LysoTracker Deep Red, CD243/MDR-1 Antibody (Monoclonal) and Fluorescein (FITC)-conjugated Affinipure Goat AntiMouse IgG $(\mathrm{H}+\mathrm{L})$ were obtained from Thermo Fisher Scientific (USA); Quantikine human vascular endothelial growth factor (VEGF) immunoassay kit was obtained from R\&D Systems, Inc. (USA). Gene transfection kit (Lipofectamine $^{\mathrm{TM}}$ 2000), Roswell Park Memorial Institute1640 (RPMI-1640), DMEM penicillin-streptomycin solution $(5 \mathrm{Ku} / \mathrm{mL})$ and fetal bovine serum were purchased from Life Technologies (USA). Negative Control siRNA (denoted as NC siRNA, scrambled sequences) (sense, 5'-UUC UCC GAA CGU GUC ACG UTT-3'; antisense, 5'-ACG UGA CAC GUU CGG AGA ATT-3'), fluorescein amidite (FAM)labeled NC siRNA (modified at the $5^{\prime}$ end of the sense strand), VEGF siRNA ${ }^{10}$ (sense, 5'-GGA GUA CCC UGA UGA GAU CdTdT-3'; antisense, 5'-GAU CUC AUC AGG GUA CUC CdTdT-3'), MDR-1-siRNA-1 (sense 5'-GCG AAG CAG UGG UUC AGG UdTdT-3'; antisense, 5'-ACC UGA ACC ACU GCU UCG CdTdT-3'), MDR-1-siRNA-2 (sense, 5'-GUG GGC ACA AAC CAG AUA AUdTdT-3'; antisense, 5'-UUA UCU GGU UUG UGC CCA CdTdT-3', MDR-1-siRNA-3 (sense, 5'-GAC CAG GUA UGC CUA UUA UdTdT-3'; antisense, 5'-AUA AUA GGC AUA CCU GGU CdTdT-3', MDR-1-siRNA-4 (sense, 5'-GGG AUA AAG AAA GCU AUU AdTdT-3'; antisense, 5'-UAA UAG CUU UCU UUA UCC CdTdT-3' were synthesized by GenePharma Co. Ltd. (Shanghai, China). Doxorubicin was purchased from Sangon Biotech (Shanghai, China).

\section{Monitoring of siRNA-Dox complex formation by fluorescence spectrometry}

We employed fluorescence spectrometry to monitor the siRNA and doxorubicin complex formation based on previous studies in which doxorubicin (thereafter denoted as Dox) intercalated within nucleic acids (plasmid or aptamer) to generate the physical complex. ${ }^{14-17}$ In general, different concentrations of Dox in a fixed volume $(50 \mu \mathrm{L})$ were 
A
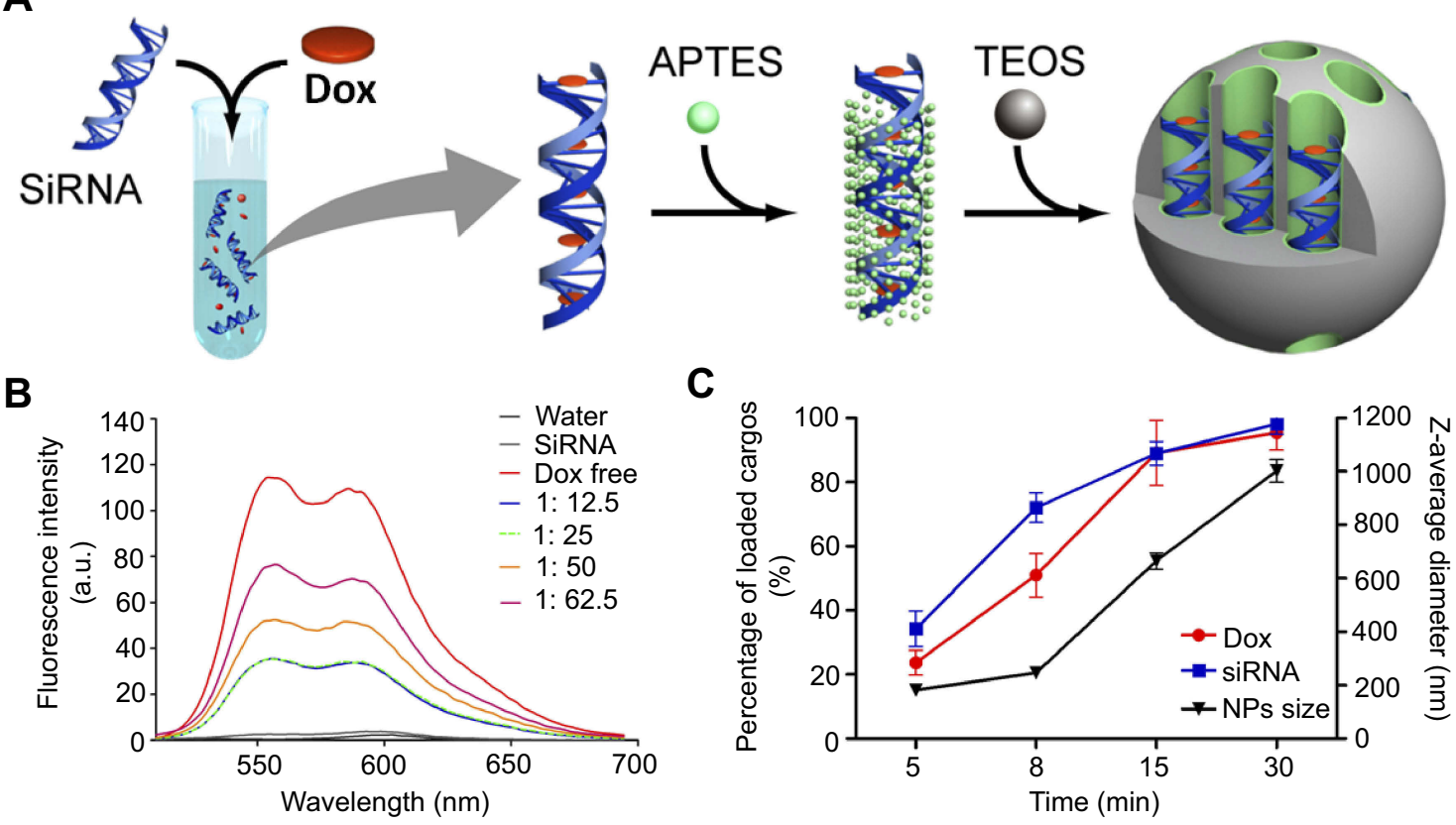

B

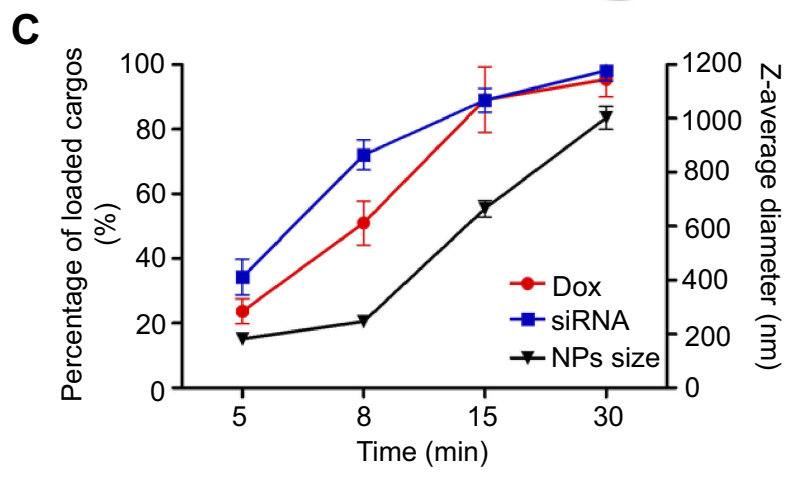

D

E



E
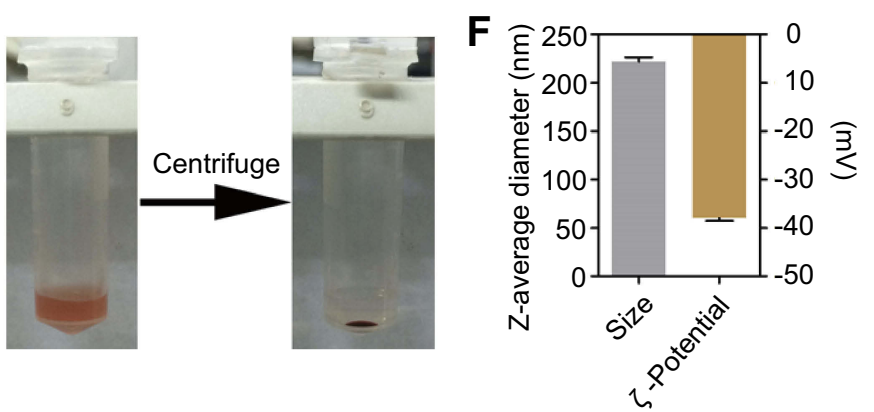

G
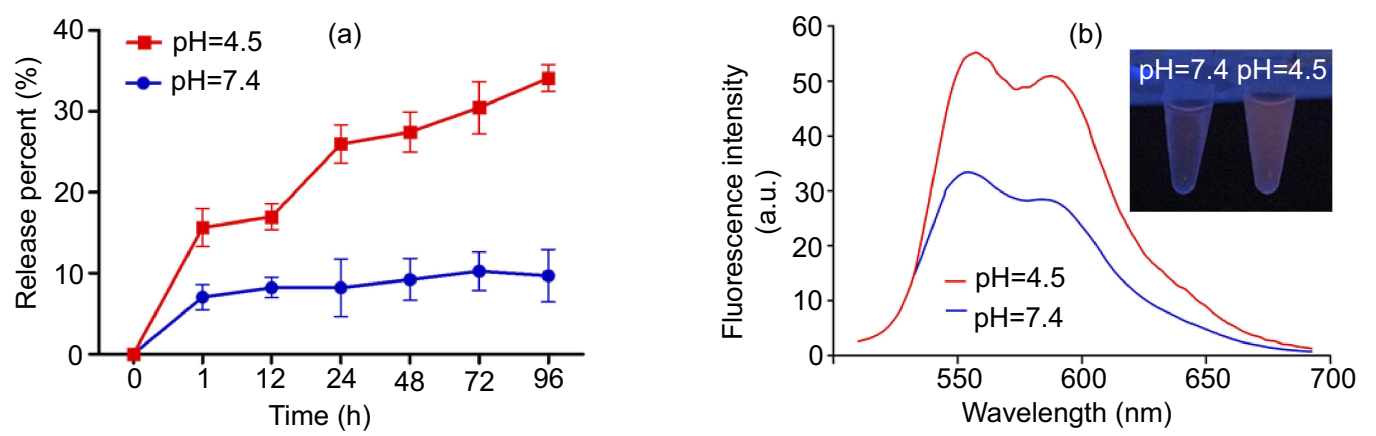

Figure I Synthesis and characterization of siRNA-Dox-SiO ${ }_{2}$ nanoparticles. (A) Schematic workflow of synthesizing siRNA-Dox-SiO ${ }_{2}$ nanoparticles. (B) Fluorescence spectra of Dox with increasing Dox concentrations to a fixed siRNA amount. (C) The time-dependent siRNA and Dox encapsulation capacities in vector (left $Y$ axis) and the corresponding varying size of siRNA-Dox-SiO ${ }_{2}$ over time (right $\mathrm{Y}$ axis). (D) TEM image of siRNA-Dox-SiO ${ }_{2}($ bar $=100 \mathrm{~nm})$. (E) siRNA-Dox-SiO ${ }_{2}$ dispersed in water (left) and after centrifugation (right). (F) Dynamic light scattering measurements of siRNA-Dox-SiO ${ }_{2}$ hydrodynamic size (diameter) and zeta potential ( $\mathrm{mV}$ ) ( $\mathrm{n}=3$ ) after synthesis. (G) (a) $\mathrm{pH}$-dependent Dox release pattern of siRNA-Dox-SiO ${ }_{2}$. (b) Representative fluorescent intensity of released Dox from siRNA-Dox-SiO ${ }_{2}$ in different $\mathrm{pH}$ PBS solution at $24 \mathrm{hr}$ time point. The inset showed the fluorescence quenched by intact siRNA-Dox-SiO 2 vectors in neutral environment (pH=7.4) using UV lamp at 24-hr time point. Abbreviations: siRNA, small interfering RNA; Dox, doxorubicin; $\mathrm{SiO}_{2}$, silica; TEM, transmission electron microscopy; PBS, phosphate-buffered saline; UV, ultraviolet.

mixed with $100 \mu \mathrm{L}$ siRNA water solution at a fixed concentration $(1 \mathrm{mg} / \mathrm{mL})$, and the fluorescence of Dox was then measured by LS 55 Luminescence Spectrometer (Perkin Elmer, USA) at excitation $480 \mathrm{~nm}$, and emission data was obtained in the interval of 520-680 nm.

\section{Preparation of siRNA-Dox-SiO 2 , siRNA- $\mathrm{SiO}_{2}$ and lipofectamine-siRNA-Dox}

For the complexing of siRNA and Dox, $100 \mu \mathrm{L}$ water solution of siRNA $(1 \mathrm{mg} / \mathrm{mL})$ was added to a $1.5 \mathrm{~mL}$ 
centrifuge tube and mixed with $50 \mu \mathrm{L}$ Dox water solution $(1 \mathrm{mg} / \mathrm{mL})$. The mixture was dispersed by vortex for $1 \mathrm{~min}$ and $0.21 \mu \mathrm{L}$ APTES and $0.23 \mu \mathrm{L}$ TEOS (1:12.5:3:3.75; siRNA: Dox: APTES: TEOS, M/M) were successively added and immediately vortexed for $1 \mathrm{~min}$ at room temperature. The obtained sample was incubated in $40^{\circ} \mathrm{C}$ water bath for 8 mins. Finally, free siRNA and Dox in the supernatant were eliminated by centrifugation at $10,000 \mathrm{rpm}$, and the precipitation was further washed using deionized water. The product siRNA-Dox- $\mathrm{SiO}_{2}$ was resuspended in deionized water for the following experiments. Similarly, siRNA-SiO nanovector could be produced without complexing with Dox before the treatment of APTES and TEOS. Lipofectamine-siRNA-Dox was produced by mixing Lipofectamine $^{\mathrm{TM}_{2}} 200$ with the prior formed siRNADox complex at $2: 1$ weight ratio of siRNA to lipofectamine.

The hydrodynamic size distribution and zeta potential of siRNA-Dox-SiO ${ }_{2}$ were determined by Dynamic light scattering (DLS) method and Zetasizer Nano ZS (Malvern, Britain), respectively. Samples were suspended in ethanol and dried on holey carbon-coated $\mathrm{Cu}$ grids, and their morphological images were obtained with a transmission electron microscopy (TEM, JEM-2010, Japan) at $200 \mathrm{kV}$ acceleration voltage.

\section{Doxorubicin releasing from the nanocarrier in vitro}

To investigate $\mathrm{pH}$-triggered Dox release, siRNA-Dox-SiO was incubated in PBS buffers of different acidity $(\mathrm{pH} 7.4$ and $\mathrm{pH} 4.5$ ) for $96 \mathrm{hrs}$ at $37^{\circ} \mathrm{C}$. At different time points, samples were subjected to a centrifuge speed of 13,200 rpm, and $25 \mu \mathrm{L}$ of the supernatant was taken out from the total volume $(500 \mu \mathrm{L})$ to test the amount of released Dox by Nanodrop 1000 at $580 \mathrm{~nm}$. Fresh buffer of $25 \mu \mathrm{L}$ was then replenished to maintain a fixed volume $(500 \mu \mathrm{L})$.

\section{Cell lines and cultures}

MCF-7 cells (a human breast adenocarcinoma cell line) were purchased from Cell Bank of Chinese Academy of Sciences (Shanghai, China), and MCF-7/MDR cells (MCF-7 cells with multidrug resistance (MDR)) were purchased from Nanjing KeyGen Biotech. Co. Ltd, China, which was a kind gift from Dr. Xiaofang Hu, Laboratory of Heat Transfer and Proteomics, Shanghai Jiao Tong University. MCF-7 and MCF-7/MDR cell lines were cultured in RMPI-1640 supplemented with 10\% fetal bovine serum (FBS; v/v) and 2\% penicillin-streptomycin
(PS; v/v). Cells were incubated at $37^{\circ} \mathrm{C}$ with $5 \% \mathrm{CO}_{2}$ in a humid cell incubator.

\section{Cytotoxicity assessment of NC siRNA- $\mathrm{SiO}_{2}$}

Cell viability of MCF-7 and MCF-7/MDR cells were measured using the CCK-8 assay. Cells were seeded at a density of $1 \times 10^{4}$ cells per well on 96-well plates and grown until approximately $80 \%$ confluence and then the following experiments were conducted. After removing the culture medium, the fresh medium containing $10 \%$ FBS and various concentrations (0-600 nM, applied siRNA concentrations) of $\mathrm{NC}$ siRNA-SiO $\mathrm{S}_{2}$ were added. Cells in the treatment of an equivalent volume of culture medium were used as a negative control, and cells treated with $2 \%$ Triton X-100 were used as a positive control. Cells were incubated with nanoparticles for $24 \mathrm{hrs}$ and subjected to CCK-8 assay following the vendor's protocol. All experiments were performed in hexaplicate, and the averaged absorbance values were normalized to the negative control.

\section{Gene knockdown efficacy of siRNA-Dox- $\mathrm{SiO}_{2}$ in vitro}

To evaluate gene silencing efficacy, MCF-7/MDR cells were grown in 6-well plates to about $80 \%$ confluence, and each well was treated with siRNA-Dox- $\mathrm{SiO}_{2}$ containing siRNA dosage of $162.5 \mathrm{nM}$ with a fixed Dox concentration $(1000 \mathrm{ng} / \mathrm{mL})$. After incubation with various siRNA vectors for $24 \mathrm{hrs}$, MCF-7/MDR cells were replenished with fresh medium and cultured for another $24 \mathrm{hrs}$. For testing the effectiveness of VEGF gene-silencing (by using VEGF specific siRNA), the conditioned medium was collected and subjected to centrifugation. An ELISA assay was then used to determine VEGF levels. For testing the silencing of the MDR-1 gene (by using MDR-1 specific siRNA), cells were collected and the total protein was extracted for measurement by BCA assay. The extracts containing $50 \mu \mathrm{g}$ of total protein were separated by $10 \%$ SDSPAGE, and the target protein was electro-transferred onto nitrocellulose membranes. The membrane was then blocked and successively incubated with primary antibody and corresponding HRPconjugated- secondary antibody. After washing, the ECL chemical reagents were added to the membrane, and their images were captured using ChemiDoc XRS (BioRad, Hercules, CA, USA). 


\section{Cytotoxicity of NC siRNA-Dox-SiO ${ }_{2}$ and MDR-I siRNA-Dox-SiO 2}

For measuring the cytotoxicity produced by NC siRNADox-SiO ${ }_{2}, \mathrm{MCF}-7$ cells were grown in 96-well plates to about $80 \%$ confluence, and each well was treated with siRNA-Dox- $\mathrm{SiO}_{2}$ (containing $162.5 \mathrm{nM} \mathrm{NC}$ siRNA) that encapsulated Dox at a fixed concentration $(1000 \mathrm{ng} / \mathrm{mL})$. After incubation with various vectors for $24 \mathrm{hrs}$, cells were subjected to CCK-8 assay following the vendor's protocol. All experiments were performed in hexaplicate, and the averaged absorbance values were normalized to negative control.

For measuring the cytotoxicity produced by MDR-1 siRNA-Dox-SiO $2, \mathrm{MCF}-7 / \mathrm{MDR}$ cells were grown in 96well plates to about $80 \%$ confluence, and each well was treated with MDR-1 siRNA-Dox-SiO ${ }_{2}$ (containing 162.5 nM MDR-1 siRNA) that encapsulated Dox at various concentrations $(500,1000,2000 \mathrm{ng} / \mathrm{mL}$, respectively), Dox $\left(2000 \mathrm{ng} / \mathrm{mL}\right.$ ) group, NC siRNA-SiO ${ }_{2}$ (containing 162.5 nM NC siRNA) and NC siRNA-Dox- $\mathrm{SiO}_{2}$ (containing $162.5 \mathrm{nM}$ NC siRNA with Dox concentration at $2000 \mathrm{ng} /$ $\mathrm{mL}$ ). After incubation for $24 \mathrm{hrs}$, the wells were replaced with fresh culture medium and incubated for another $36 \mathrm{hrs}$, followed by CCK-8 assay. Control groups also included no treatment and Dox only. All experiments were performed in hexaplicate, and the averaged absorbance values were normalized to negative control (without treatment).

\section{Intracellular localization of siRNA-Dox- $\mathrm{SiO}_{2}$}

To monitor the intracellular trafficking of siRNA-Dox$\mathrm{SiO}_{2}, \mathrm{MCF}-7 / \mathrm{MDR}$ cells were seeded onto glass-bottom dishes at a density of $2 \times 10^{4}$ cells per dish and incubated at $37^{\circ} \mathrm{C}$ for $4 \mathrm{hrs}$ and $24 \mathrm{hrs}$. The growth medium was then replaced with fresh medium containing siRNA-Dox-SiO (siRNA modified with fluorescein amidite). Before imaging, cells were stained with LysoTracker ${ }^{\circledR}$ Deep Red for lysosome detection and treated with Hochest33342 for nucleus visualization. Confocal laser scanning microscopy (CLSM, Leica SP5 II, Germany) was used to estimate the intracellular distribution of siRNA, Dox and lysosome.

\section{Statistical analysis}

Data are expressed as mean $\pm \mathrm{SD}$. The significance of difference was analyzed by one- or two-way ANOVA using the GraphPad Prism 5 software. Differences with $p<0.01$ were considered statistically significant.

\section{Results and discussion Formation of the siRNA-Dox complex and its cytotoxicity}

Physical interactions between doxorubicin (thereafter referred as Dox) and nucleic acids are well known, with Dox preferentially binding to the $5^{\prime}-\mathrm{GC}-3^{\prime}$ or $3^{\prime}-\mathrm{GC}-5^{\prime}$ sequences, owing to the presence of flat aromatic rings. Taking advantage of such properties, researchers sought to develop certain formulations by complexing plasmid/apatmer with Dox, and most of these complexes, when applied by delivery systems, had shown a marked inhibition of tumor growth. ${ }^{14-17}$ Inspired by these exciting studies, we hypothesized that Dox could also intercalate into doublestranded regions of siRNA to form a physical complex. In the current study, we fixed the siRNA concentration, added Dox at increasing concentrations but at a fixed volume, and monitored the fluorescence spectrum of Dox. Bare siRNA exhibited no fluorescence, but when the concentration of Dox increased from 1: 12.5 to 1: 25 (siRNA to Dox, $M / M)$, the fluorescence signals remained nearly unchanged, suggesting that Dox intercalated with the double-stranded siRNA and hence quenched fluorescence (Figure 1B). Fluorescence signal started to increase again when the Dox concentration reached 1:50 or higher. The spectrum of free Dox was also included for comparison (Figure 1B). We chose the 1: 12.5 molar equivalence of siRNA to Dox for further experiments.

Next, whether the prepared siRNA-Dox complex formation could influence each component's function remained to be determined. Here, we chose MCF-7, a common breast cancer cell line and its derived drug-resistant MCF-7/MDR cells for the following studies. First, we determined the cytotoxicity of Dox in MCF-7 and MCF-7/MDR cells. As a result, MCF-7/MDR cells were much more resistant to Dox than MCF-7 cells with $\mathrm{IC}_{50}$ at around $1000 \mathrm{ng} / \mathrm{mL}$ (Figure S1A). Then, we conducted cytotoxicity assay in MCF-7 cells, showing that Lipofectamine ${ }^{\mathrm{TM}_{2}} 2000-\mathrm{NC}$ siRNA-Dox (applied NC siRNA concentration at $125 \mathrm{nM}$ with Dox concentration at $1000 \mathrm{ng} / \mathrm{mL}$ ) had similar cytotoxicity as free Dox at equivalent concentration, and the control groups (control, Lipofecatamine and Lipofectamine ${ }^{\mathrm{TM}} 2000-\mathrm{NC}$ siRNA) presented negligible toxicity (Figure S1B). Meanwhile, in vitro RNAi efficacy experiment revealed that Lipofectamine ${ }^{\mathrm{TM}} 2000$-VEGF siRNA-Dox (applied VEGF siRNA at $125 \mathrm{nM}$ with Dox concentration at $1000 \mathrm{ng} / \mathrm{mL}$ ) was as effective in silencing the target gene as Lipofectamine ${ }^{\mathrm{TM}} 2000$-VEGF siRNA at 
equivalent siRNA dosage in MCF-7/MDR cells (instead of MCF-7 cells, in order to eliminate the toxic influence involved with the use of Dox). In the three other groups (control, Lipofectamine and Dox), no gene knockdown was observed (Figure S1C). Collectively, these results suggested that Dox could intercalate into siRNA groove readily via noncovalent conjugation to form the physical complex and that the formation of such complex did not affect each component's own function in cells.

\section{Preparation and characterization of siRNA-Dox-SiO ${ }_{2}$ and determination of dox release from the complex}

The synthesized complex of siRNA-Dox provided a convenient tool for targeted and combination cancer therapy. Inspired by previous studies in which anionic surfactants such as DNA or RNA could be used as templates to synthesize anionic-surfactant-templated mesoporous silicas mediated by CSDA, ${ }^{19-21}$ we speculated that siRNA or siRNA-Dox complex could also be appropriate to serve as novel anionic surfactants for the synthesis of siRNA/ siRNA-Dox-based silica nanoparticles, by the above-mentioned self-assembly method. To this end, we adopted a sequential assembly approach (Figure 1A): first the siRNA-Dox complex was produced via non-covalent physical interactions, electrostatic interactions between the complex and the positively charged amino site of APTES, and co-condensation with TEOS assembled subsequently to form the silica framework at an appropriate molar proportion (siRNA: Dox: APTES: $\mathrm{TEOS}=1$ : 12.5: 3: 3.75). Interestingly, the amount of encapsulated siRNA and Dox in this nanocarrier was determined by the reaction time. As shown in Figure 1C, loaded quantities of siRNA and Dox in the nanocarrier increased steadily over time: specifically at the 8-min timepoint, loaded siRNA and Dox reached about $70 \%$ and about $50 \%$ of the total capacity, respectively; over 15-30 mins, the loaded siRNA and Dox almost maintained at a steady level ( $\sim 85 \%$ or higher). In parallel, the nanoparticle size increased as the siRNA and Dox-loaded volumes increased over reaction time (Figure 1C). Taken together, the loading capacities of siRNA and Dox and nanocarrier size could be readily controlled by reaction time. For the current study, we chose 8 mins as the reaction termination time point, producing nanoparticles that consistently contained siRNA ( $\sim 75 \%$ of total) and Dox ( $\sim 50 \%$ of total), with a uniform size of about $250 \mathrm{~nm}$. We characterized the physical properties of these nanoparticles. TEM image of
siRNA-Dox- $\mathrm{SiO}_{2}$ showed the nanoparticle size to be about $220 \mathrm{~nm}$ (Figure 1D). The presence of Dox in this nanocarrier was evidenced by the red precipitation compared with that before centrifugation (Figure 1E). DLS analysis revealed the nanocarrier's diameter at $240 \pm 1.5 \mathrm{~nm}$, along with zeta potential of the nanoparticle that was approximately $-38 \mathrm{mV}$ (Figure 1F), which was generally regarded suitable for cellular endocytosis via the strong electrostatic interactions between silanol groups of silica nanoparticles and trimethyl-ammonium head groups of the cellular membrane. $^{22}$ In comparison with several published siRNA/Dox co-delivery systems, ${ }^{4,13,23}$ our method has the ability to synthesize co-delivery vectors conveniently in about 10 mins without prior preparation of inorganic materials and eliminate drug encapsulation, leading overall to improved drug loading and decreased preparation time.

In vitro Dox release study was conducted at $37^{\circ} \mathrm{C}$ in sterile PBS buffer at $\mathrm{pH} 4.5$ and 7.4, simulating the acidic lysosomes/ endosomes and the normal physiological environment, respectively. Results confirmed that Dox was slowly and steadily released $(\sim 8 \%)$ at $\mathrm{pH} 7.4$, extending up to $96 \mathrm{hrs}$, whereas at $\mathrm{pH} 4.5$, Dox was released more rapidly ( $>30 \%$ ) within $96 \mathrm{hrs,}$ suggesting Dox release from the nanoparticle was both timeand $\mathrm{pH}$-dependent (Figure $1 \mathrm{G}-\mathrm{a}$ and $\mathrm{b}$ ). $\mathrm{pH}$ sensitivity of siRNA-Dox- $\mathrm{SiO}_{2}$ was an advantage for drug delivery. During circulation or in the extracellular space with a $\mathrm{pH}$ of approximately 7.4, Dox was only released from the nanocarrier at a basal level. Contrarily, when siRNA-Dox- $\mathrm{SiO}_{2}$ was internalized by tumor cells and entered endosomal/lysosomal compartments, Dox was quickly released from the particles to facilitate the killing of cancer cells. To test the stability of siRNA in siRNA-Dox-SiO ${ }_{2}$ nanocarrier, siRNA-release behavior in PBS was monitored. Results reflected that the amount of siRNA was slowly released from the nanocarrier and eventually reached the plateau at $72 \mathrm{hrs}$ with about $85 \%$ of the total loaded siRNA (Figure S2A), as corroborated by the agarose gel electrophoresis result (Figure S2B) that revealed the highly effective retardation and protection of siRNA by the nanocarrier.

\section{Cytotoxicity and gene silencing efficacy of siRNA-Dox-SiO 2}

Although silica-based materials are generally regarded biocompatible and suitable for in vivo use, ${ }^{24,25}$ the cytotoxicity of siRNA-SiO ${ }_{2}$ delivery system (similarly prepared as siRNA-Dox- $\mathrm{SiO}_{2}$ but without Dox) remains to be tested prior to further studies. The cell viability of 

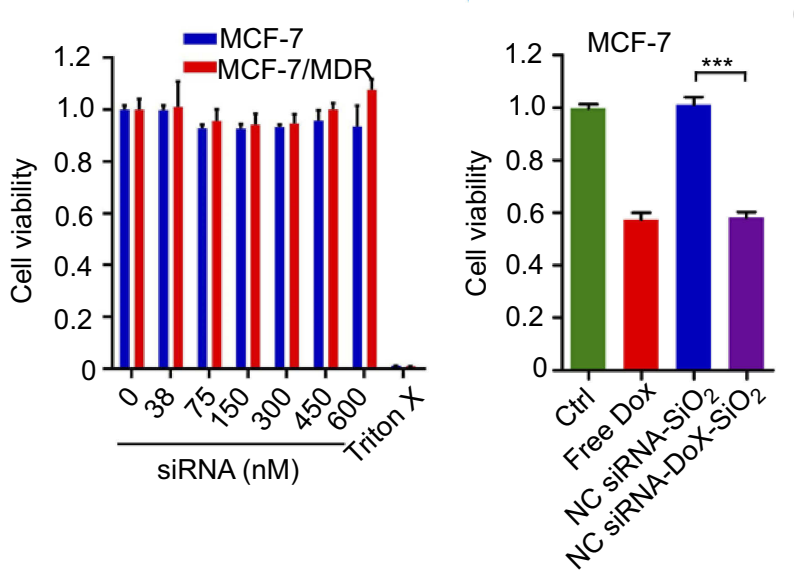

C

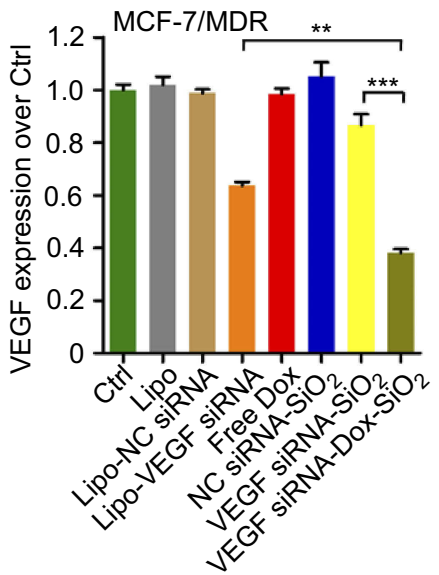

D

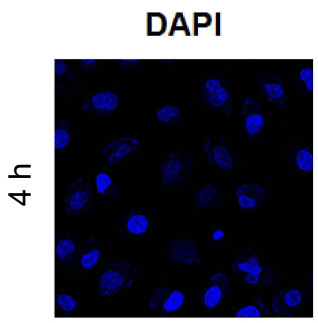

FAM-siRNA

Dox

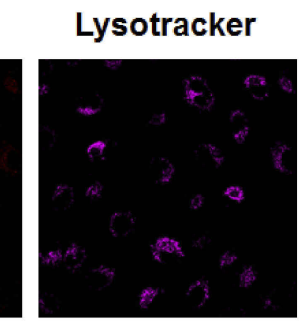

Merge



Zoomed
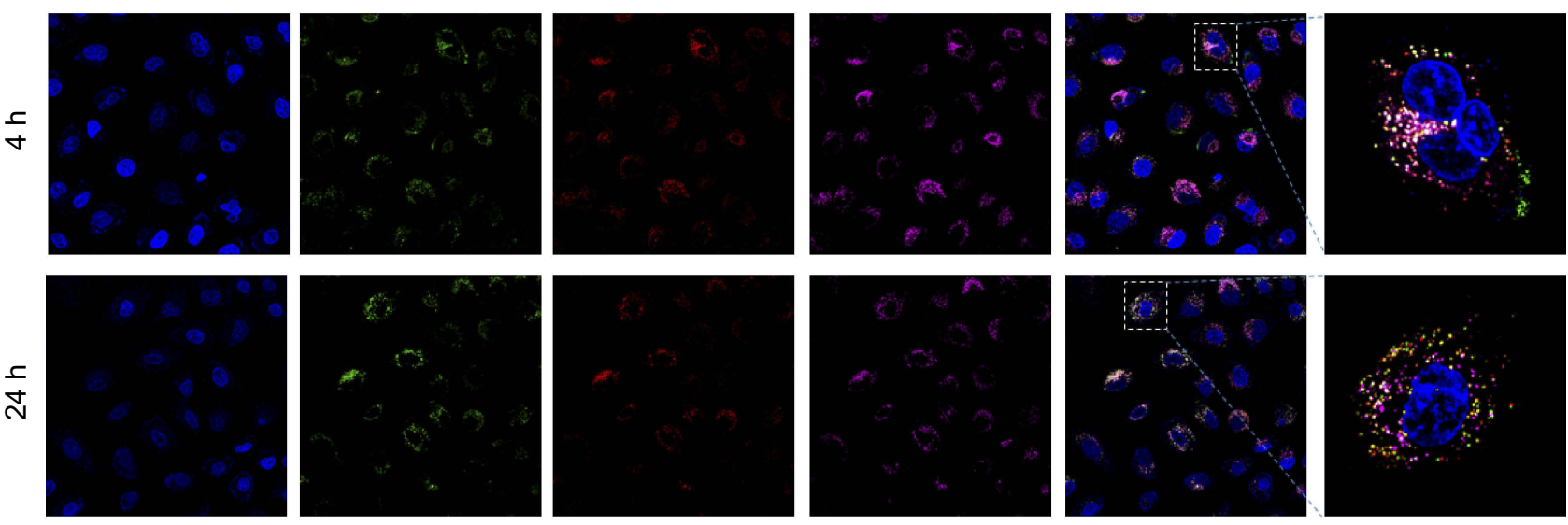

Figure 2 The biological function tests of siRNA-Dox-SiO 2 nanoparticles. (A) Cytotoxicity of NC siRNA-SiO 2 in MCF-7 and MCF-7/MDR cell lines with various nanocarrier concentrations (applied siRNA concentrations: 0, 38, 75, I50, 300, 450, $600 \mathrm{nM}$ ). (B) Cytotoxicity of MCF-7 cells treated with various formulations. (C) VEGF expressions in MCF7/MDR cells regulated by various formulations. Lipo, Lipofectamine ${ }^{T M} 2000$; Lipo-NC siRNA, NC siRNA loaded Lipofectamine ${ }^{T_{M}} 2000$; Lipo-VEGF siRNA, VEGF siRNA loaded Lipofectamine ${ }^{\mathrm{TM}} 2000$. Data are represented as the means \pm S.D. $(* * p<0.001 ; n=3 ; * * * p<0.000$ I; $n=3)$. (D) Evaluation of endosomal escapability of FAM-NC siRNA-Dox-SiO ${ }_{2}$. Fluorescence images of MCF-7/MDR cells incubated with FAM-NC siRNA-Dox-SiO 2 vectors for 4 hrs and 24 hrs using confocal laser scanning microscopy (CLSM).

Abbreviations: NC siRNA, negative small interfering RNA; Dox, doxorubicin; $\mathrm{SiO}_{2}$, silica.

MCF-7 and MCF-7/MDR incubated with different concentrations of NC siRNA- $\mathrm{SiO}_{2}$ (applied siRNA concentration, from 0 to $600 \mathrm{nM}$ ) for $24 \mathrm{hrs}$ were measured by the CCK8 assay (Figure 2A). All concentrations exhibited negligible cytotoxicity even at $600 \mathrm{nM}$ for both MCF-7 and MCF-7/MDR cell lines compared to that of nearly $100 \%$ cell death in treatment of $2 \%$ Triton X-100 that has widely been used as a positive control group, ${ }^{26,27}$ indicating that siRNA-SiO $\mathrm{S}_{2}$-based nanocarrier presented great biocompatibility with cells, and possibly could be suitable for in vitro/in vivo biological applications.

Following biocompatible analysis of siRNA-SiO nanoparticles, a similar study on siRNA-Dox complex that whether siRNA and Dox in the siRNA-Dox- $-\mathrm{SiO}_{2}$ nanoparticle could interfere with their own functions should be confirmed. We again measured the cytotoxicity of NC-siRNA-Dox in MCF-7 cells and chose the VEGF gene and tested for target gene silencing efficacy on MCF7/MDR cells (to eliminate the toxic influence from Dox). In MCF-7 cells, NC siRNA-Dox-SiO 2 (applied $162.5 \mathrm{nM}$ NC siRNA with Dox concentration at $1000 \mathrm{ng} / \mathrm{mL}$ ) showed very similar cytotoxicity levels compared with an equivalent amount of free Dox, while the control groups presented undetectable toxicity (Figure 2B). In parallel, VEGF siRNA-Dox-SiO 2 (applied $162.5 \mathrm{nM}$ VEGF siRNA with Dox concentration at $1000 \mathrm{ng} / \mathrm{mL}$ ) caused significantly better VEGF silencing than Lipofectamine ${ }^{\mathrm{TM}} 2000$-VEGF siRNA did at an equivalent siRNA dosage (Figure 2C). Five other groups (Control, Lipofectamine ${ }^{\mathrm{TM}} 2000$, Lipofectamine ${ }^{\mathrm{TM}} 2000-\mathrm{NC}$ siRNA, Dox, NC siRNA-SiO 2 ) showed no VEGF knockdown in MCF-7/MDR cells, as shown in Figure 2C. Interestingly, 
VEGF siRNA-Dox-SiO ${ }_{2}$ showed better VEGF knockdown, plummeting to about $30 \%$ of the control, than VEGF siRNA-SiO 2 did in which VEGF level only dropped to about $85 \%$ of the control group (Figure 2C). This improved gene silencing capacity of VEGF siRNADox- $\mathrm{SiO}_{2}$ in comparison to VEGF siRNA-SiO 2 plausibly resulted from Dox intercalation that not only stabilized siRNA, but also mediated timely escape of siRNA from endosomes/lysosomes. $^{26,28,29}$ Initial evidence of this enhanced siRNA escape was provided by confocal microscopy visualizing the cellular localization FAM-labeled siRNA from the two types of nanoparticles siRNA-Dox$\mathrm{SiO}_{2}$ (Figure 2D) and siRNA-SiO ${ }_{2}$ (Figure S3), in which the most FAM-labeled siRNA carried by $\mathrm{siRNA}^{-\mathrm{SiO}_{2}}$ nanoparticles were trapped in endosomes/lysosomes after transfection (Figure S3), whereas the siRNA encapsulated by siRNA-Dox-SiO $\mathrm{S}_{2}$ nanoparticles were nearly completely separated from endosomes/lysosomes (Figure 2D). Taken together, these experiments demonstrated, in principle, siRNA-Dox- $\mathrm{SiO}_{2}$ as a novel co-delivery system to simultaneously deliver Dox and siRNA into cancer cells. Such a system could produce effective target gene silencing and induce marked cytotoxicity, suggesting its potential use for combination cancer therapy, especially when the target gene was related to MDR.

\section{Cytotoxicity induced by MDR-I siRNA- Dox-SiO ${ }_{2}$ in MCF-7/MDR cells}

To demonstrate that our co-delivery could target MDR, we chose the target gene of MDR-1. MDR to chemotherapeutic agents, such as Dox, anthracyclines and taxanes, was commonly associated with cancer cell overexpression of drug transporter proteins such as P-gp, which is encoded by the ABCB2 gene. $^{30,31}$ MCF-7 expressed negligible P-gp while MCF-7/MDR expressed it at a higher level, as confirmed by flow cytometry assay (Figure S4A). By contrast, higher P-gp expression in MCF-7/MDR cells was highly associated with reduced Dox retention in cytoplasm compared with that tested in MCF-7 cells (Figure S4B). We then tested four MDR-1 siRNAs to target human MDR-1 gene. Of the four siRNAs, MDR-1 siRNA-3 (L-S3) potently suppressed the expression of $\mathrm{P}$-gp proteins in MCF-7/MDR cells as compared with the other siRNAs, after transfection with Lipofectamine ${ }^{\mathrm{TM}} 2000$ (Figure 3A-a). Based on these results, we selected MDR-1 siRNA-3 for the following experiments (thereafter, MDR-1 siRNA-3 denoted as MDR-1 siRNA). Next, we combined MDR-1 siRNA with Dox to be assembled subsequently to form MDR-1 siRNA-Dox-SiO ${ }_{2}$ after addition of APTES and TEOS. MDR-1 siRNA-Dox$\mathrm{SiO}_{2}$ exhibited highly effective inhibition of $\mathrm{P}$-gp expression compared to MDR-1 siRNA-SiO 2 (Figure 3A-b). This high gene-silencing efficacy of MDR-1 siRNA-Dox-SiO ${ }_{2}$ was considered as a result of Dox intercalation, also corroborated by the findings in Figure $2 \mathrm{C}$.

Similarly, synergism of MDR-1 siRNA and Dox via the siRNA-Dox-SiO $\mathrm{S}_{2}$ nanocarrier was also evident in cytotoxicity assays, where the combination treatment caused a significant inhibition of cell viability compared to each treatment alone or nanocarrier containing $\mathrm{NC}$ siRNA in MCF-7/MDR cells, as shown in Figure 3B. Meanwhile, we prepared various MDR-1 siRNA-Dox$\mathrm{SiO}_{2}$ formulations that included fixed siRNA concentration $(162.5 \mathrm{nM})$ with Dox concentrations at 500, 1000 and $2000 \mathrm{ng} / \mathrm{mL}$, respectively. Cytotoxicity assay in MCF-7/MDR cells $60 \mathrm{hrs}$ after incubation with these formulations showed that highest cell inhibition was observed at the Dox concentration of $2000 \mathrm{ng} / \mathrm{mL}$ $(* * * p<0.0001)$, followed by 1000 and $500 \mathrm{ng} / \mathrm{mL}$, at a concentration-dependent manner (Figure 3B). In contrast, free doxorubicin at $2000 \mathrm{ng} / \mathrm{mL}$ posed negligible toxicity to MCF-7/MDR cells (Figures 3B and S1A). In parallel, quantitation of the apoptotic rate of different formulations against MCF-7/MDR cells were measured by flow cytometry using Annexin V staining method (Figure S5). Consequently, co-occurrence of Dox and MDR-1 siRNA via nanocarrier in MCF-7/MDR cells exhibited the highest cell apoptosis at the Dox concentration of $2000 \mathrm{ng} /$ $\mathrm{mL}$, followed by 1000 and $500 \mathrm{ng} / \mathrm{mL}$. These results illustrated that knockdown of MDR-1 re-sensitized the multidrug-resistant MCF-7/MDR cells. To better determine the intracellular Dox concentration, flow cytometry and confocal microscopy were performed after treatment with MDR-1 siRNA-Dox-SiO ${ }_{2}, \mathrm{NC}$ siRNA-Dox-SiO and free doxorubicin. Abundant red signals distributed in the cytoplasm and the nucleus were detected in the MDR-1 siRNA-Dox-SiO 2 group, as compared with weaker red spots in NC siRNA-Dox- $\mathrm{SiO}_{2}$ and free doxorubicin groups (Figure $3 \mathrm{C}-\mathrm{a}-\mathrm{c}$ ). In parallel, total red fluorescence among various groups was determined by flow cytometry, which indicated that the intracellular Dox content after treatment with MDR-1 siRNA-Dox-SiO ${ }_{2}$ in MCF-7/MDR cells was approximate 9 times higher than free Dox group (Figure 3C-d). In conclusion, we showed the synergistic effect of MDR-1 siRNA/Dox combination delivered by self-assembly inorganic silica nanocarrier in 
A

(a)

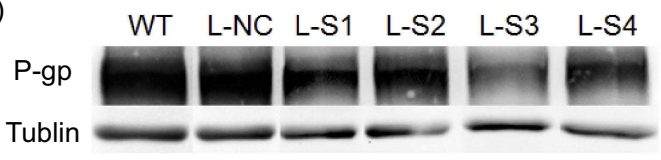

(b)

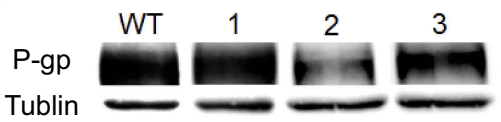

B



C



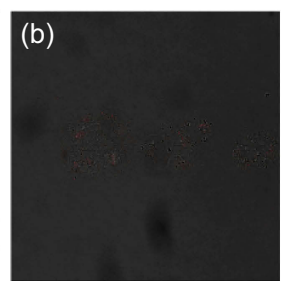
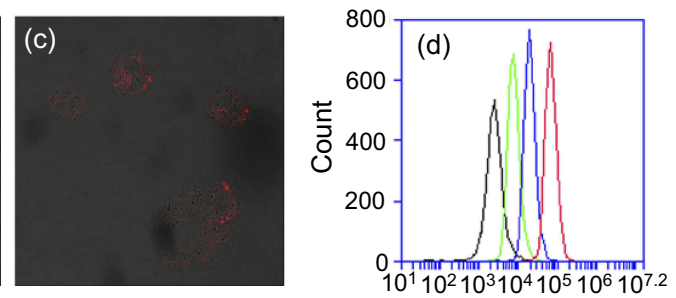

Figure 3 The cytotoxicity of MDR-I siRNA-Dox-SiO 2 nanoparticles against MCF-7/MDR cells. (A) (a) P-gp expression determined through Western blot in treatment of various MDR-I siRNAs transfected by Lipofectamiane ${ }^{T M} 2000$ in MCF-7/MDR cells. WT, without treatment; L-NC, Lipofectamiane ${ }^{T M} 2000-N C$ siRNA; L-SI, Lipofectamiane ${ }^{T M}$ 2000-MDR-I siRNA-I; L-S2, Lipofectamiane ${ }^{T M}$ 2000-MDR-I siRNA-2; L-S3, Lipofectamiane ${ }^{\text {TM }}$ 2000-MDR-I siRNA-3; L-S4, Lipofectamiane ${ }^{T M}$ 2000-MDR-I siRNA-4. (b) P-gP expression measured by Western blot in treatment of various silica-based siRNA formulations in MCF-7/ MDR cells. WT, without treatment; I, NC siRNA-Dox-SiO 2 ; 2, MDR-I siRNA-Dox-SiO 2 ; 3, MDR-I siRNA-SiO 2 . (B) Cytotoxicity of MDR-I siRNA-Dox-SiO 2 (MDR siRNA refer to MDR siRNA-3) containing different Dox concentrations determined by CCK-8 assay in MCF-7/MDR cells. MDR-I siRNA-Dox-SiO ${ }_{2}-\mathrm{I}_{\text {, Dox }}$ concentration at $500 \mathrm{ng} / \mathrm{mL}$; MDR-I siRNA-Dox-SiO $2-2$, Dox concentration at $1000 \mathrm{ng} / \mathrm{mL}$; MDR-I siRNA-Dox-SiO ${ }_{2}-3$, Dox concentration at $2000 \mathrm{ng} / \mathrm{mL}$. Free Dox group with concentration of $2000 \mathrm{ng} / \mathrm{mL}$. All of groups contained the same siRNA value. $* p<0.01$; $* * p<0.001 ; * * *<<0.000 \mathrm{I}, \mathrm{n}=5$. (C) The cellular Dox retention observed by CLSM (confocal laser scanning microscopy) $60 \mathrm{hrs}$ after treating with Dox (a), NC siRNA-Dox-SiO 2 (b) and MDR-I siRNA-Dox-SiO 2 (c). (d) The cellular Dox retention determined by FCM (flow cytometry) 60 hrs after treating with Dox (green line), NC siRNA-Dox-SiO 2 (blue line) and MDR-I siRNA-Dox- $\mathrm{SiO}_{2}$ (red line); the black line denoted as the control group (without any nanocarrier and Dox). Bar=50 $\mu \mathrm{m}$.

Abbreviations: $\mathrm{NC}$ siRNA, negative small interfering RNA; Dox, doxorubicin; $\mathrm{SiO}_{2}$, silica.

overcoming drug resistance in MCF-7/MDR cells. This nanocarrier could suppress the P-gp levels and promote the Dox retention in MCF-7/MDR cells, overall leading to enhanced cell inhibition. Nevertheless, these results demonstrated in principle the usefulness of the nanocarrier to inhibit cancer cell growth in vitro alone. Future in vivo investigations are warranted.

\section{Conclusion}

In this study, we developed a novel and readily prepared co-delivery system of siRNA and doxorubicin via selfassembly of inorganic silica nanoparticles. Physical interactions between doxorubicin and siRNAs facilitated a fast and reversible formation of siRNA-Dox complex. This complex then could be used as templates for synthesizing silica-based siRNA and Dox co-delivery system by introducing APTES (a kind of co-structuredirecting agent, CSDA) and TEOS (a type of inorganic silicon) successively. siRNA and doxorubicin were encapsulated into this nanocarrier with high loading capacities and their own biological functions were not compomised. Consequently, transfection of MDR-1 siRNA-Dox-SiO 2 into MCF-7/MDR cells could improve their sensitivity to Dox, overall leading to enhanced chemotherapeutic cytotoxicity.

\section{Acknowledgments}

This study is supported by grants from National Natural Science Foundation of China [No. 81701828], Natural Science Foundation of Zhejiang Province [No.
[Nound LY16H180008], Wenzhou Science and Technology Bureau Foundation [No. Y20150082].

\section{Disclosure}

The authors report no conflicts of interest in this work. 


\section{References}

1. Konieczkowski DJ, Johannessen CM, Garraway LA. A convergencebased framework for cancer drug resistance. Cancer Cell. 2018;33 (5):801-815. doi:10.1016/j.ccell.2018.03.025

2. Bar-Zeev M, Livney YD, Assaraf YG. Targeted nanomedicine for cancer therapeutics: towards precision medicine overcoming drug resistance. Drug Resist Updat. 2017;31:15-30. doi:10.1016/j. drup.2017.05.002

3. Li Y, Gao X, Yu Z, et al. Reversing multidrug resistance by multiplexed gene silencing for enhanced breast cancer chemotherapy. ACS Appl Mater Interfaces. 2018;10(18):15461-15466. doi:10.1021/ acsami. $8 \mathrm{~b} 02800$

4. Meng H, Mai WX, Zhang H, et al. Codelivery of an optimal drug/ siRNA combination using mesoporous silica nanoparticles to overcome drug resistance in breast cancer in vitro and in vivo. ACS Nano. 2013;7(2):994-1005. doi:10.1021/nn305697q

5. Kanasty R, Dorkin JR, Vegas A, Anderson D. Delivery materials for siRNA therapeutics. Nat Mater. 2013;12(11):967-977. doi:10.1038/ nmat 3765

6. Whitehead KA, Langer R, Anderson DG. Knocking down barriers: advances in siRNA delivery. Nat Rev Drug Discov. 2009;8(2):129138. doi:10.1038/nrd2998

7. Xu X, Wu J, Liu Y, et al. Multifunctional envelope-type siRNA delivery nanoparticle platform for prostate cancer therapy. ACS Nano. 2017;11(3):2618-2627. doi:10.1021/acsnano.6b07195

8. Chen Y, Wang X, Zhang DS, Gu H. Highly effective antiangiogenesis via magnetic mesoporous silica-based siRNA vehicle targeting the VEGF gene for orthotopic ovarian cancer therapy. Int $J$ Nanomed. 2015;10:2579-2594.

9. Kim HJ, Kim A, Miyata K, Kataoka K. Recent progress in development of siRNA delivery vehicles for cancer therapy. Adv Drug Deliv Rev. 2016;104:61-77. doi:10.1016/j.addr.2016.06.011

10. Chen Y, Gu H, Zhang DS-Z, et al. Highly effective inhibition of lung cancer growth and metastasis by systemic delivery of siRNA via multimodal mesoporous silica-based nanocarrier. Biomaterials. 2014;35(38):10058-10069. doi:10.1016/j. biomaterials.2014.01.026

11. Batlle E, Clevers H. Cancer stem cells revisited. Nat Med. 2017;23 (10):1124-1134. doi:10.1038/nm.4265

12. Wang $\mathrm{D}, \mathrm{Xu} \mathrm{X}$, Zhang $\mathrm{K}$, et al. Codelivery of doxorubicin and MDR1-siRNA by mesoporous silica nanoparticles-polymerpolyethylenimine to improve oral squamous carcinoma treatment. Int $J$ Nanomed. 2018;13:187-198. doi:10.2147/IJN.S177627

13. Kwak G, Jo SD, Kim D, et al. Synergistic antitumor effects of combination treatment with metronomic doxorubicin and VEGF-targeting RNAi nanoparticles. J Control Release. 2017;267:203-213. doi:10.1016/j.jconrel.2017.08.015

14. Han L, Huang R, Li J, Liu S, Huang S, Jiang C. Plasmid pORFhTRAIL and doxorubicin co-delivery targeting to tumor using peptide-conjugated polyamidoamine dendrimer. Biomaterials. 2011;32 (4):1242-1252. doi:10.1016/j.biomaterials.2010.09.070

15. Huang S, Shao K, Liu Y, et al. Tumor-targeting and microenvironment-responsive smart nanoparticles for combination therapy of antiangiogenesis and apoptosis. ACS Nano. 2013;7(3):2860-2871. doi: $10.1021 / \mathrm{nn} 305697 \mathrm{q}$
16. Jeong H, Lee SH, Hwang Y, et al. Multivalent aptamer-RNA conjugates for simple and efficient delivery of doxorubicin/siRNA into multidrug-resistant cells. Macromol Biosci. 2017;17:4. doi:10.1002/ mabi. 201700070

17. Bagalkot V, Farokhzad OC, Langer R, Jon S. An aptamer-doxorubicin physical conjugate as a novel targeted drug-delivery platform. Angew Chem Int Ed Engl. 2006;45(48):8149-8152. doi:10.1002/anie.200602251

18. Han L, Jin C, Liu B, Che S. DNA-silica mineralization: the formation of exceptional two dimensional-square $\mathrm{p} 4 \mathrm{~mm}$ symmetry by a structural transformation. Chem Mater. 2012;24(3):504-511. 10.1021/ cm202874w.

19. Che S, Garcia-Bennett AE, Yokoi T, et al. A novel anionic surfactant templating route for synthesizing mesoporous silica with unique structure. Nat Mater. 2003;2(12):801-805. doi:10.1038/nmat1022

20. Liu B, Yao Y, Che S. Template-assisted self-assembly: alignment, placement, and arrangement of two-dimensional mesostructured DNA-silica platelets. Angew Chemie. 2013;125(52):14436-14440. doi:10.1002/ange.201307897

21. Jin C, Qiu H, Han L, Shu M, Che S. DNA transcription into diverse porous silicas by a co-structure directing route: chiral, ring and ordered nanochannel arrays. Chem Commun (Camb). 2009;23:3407-3409. doi:10.1039/b900614a

22. He C, Hu Y, Yin L, Tang C, Yin C. Effects of particle size and surface charge on cellular uptake and biodistribution of polymeric nanoparticles. Biomaterials. 2010;31(13):3657-3666. doi:10.1016/j. biomaterials. 2010.01.042

23. Chen AM, Zhang M, Wei D, et al. Co-delivery of doxorubicin and Bcl-2 siRNA by mesoporous silica nanoparticles enhances the efficacy of chemotherapy in multidrug-resistant cancer cells. Small. 2009;5(23):2673-2677. doi:10.1002/smll.200900621

24. Tang F, Li L, Chen D. Mesoporous silica nanoparticles: synthesis, biocompatibility and drug delivery. Adv Mater. 2012;24:1504-1534. doi:10.1002/adma.201104763

25. Lu J, Liong M, Li Z, Zink JI, Tamanoi F. Biocompatibility, biodistribution, and drug-delivery efficiency of mesoporous silica nanoparticles for cancer therapy in animals. Small. 2010;6(16):1794-1805. doi:10.1002/smll.201000538

26. Jain A, Barve A, Zhao Z, Jin W, Cheng K. Comparison of avidin, neutravidin, and streptavidin as nanocarriers for efficient siRNA delivery. Mol Pharm. 2017;14(5):1517-1527. doi:10.1021/acs. molpharmaceut.6b00933

27. Zhao Z, Li Y, Jain A, et al. Development of a peptide-modified siRNA nanocomplex for hepatic stellate cells. Nanomedicine. 2018;14(1):51-61. doi:10.1016/j.nano.2017.08.017

28. Shukla RS, Jain A, Zhao Z, Cheng K. Intracellular trafficking and exocytosis of a multi-component siRNA nanocomplex. Nanomedicine. 2016;12(5):1323-1334. doi:10.1016/j.nano.2016.02.003

29. Wojnilowicz M, Glab A, Bertucci A, Caruso F, Cavalieri F. Superresolution imaging of proton sponge-triggered rupture of endosomes and cytosolic release of siRNA. ACS Nano. 2019;13(1):187202. 10.1021/acsnano. 8 b05151.

30. Xiong XB, Lavasanifar A. Traceable multifunctional micellar nanocarriers for cancer-targeted co-delivery of MDR-1 siRNA and doxorubicin. ACS Nano. 2011;5(6):5202-5213. doi:10.1021/nn202666w

31. Creixell M, Peppas NA. Co-delivery of siRNA and therapeutic agents using nanocarriers to overcome cancer resistance. Nano Today. 2012;7(4):367-379. doi:10.1016/j.nantod.2012.06.013 


\section{Supplementary materials}

\section{Supplementary Methods}

\section{siRNA releasing from the nanocarrier in vitro}

To investigate siRNA release, siRNA-Dox- $\mathrm{SiO}_{2}$ was incubated in PBS buffer for $96 \mathrm{hrs}$ at $37{ }^{\circ} \mathrm{C}$. At different time points, samples were subjected to a centrifugation speed of $13,200 \mathrm{rpm} .25 \mu \mathrm{L}$ of the supernatant was taken out from the total volume $(500 \mu \mathrm{L})$ to test the amount of released siRNA by Nanodrop 1000. $25 \mu \mathrm{L}$ fresh buffer was then replenished to maintain a fixed volume $(500 \mu \mathrm{L})$.

Apoptosis induced by MDR-1 siRNA-Dox-SiO ${ }_{2}$ in vitro The MCF-7/MDR cells were seeded in 6-well plates to about $80 \%$ confluence, and each well was treated with
MDR-1 siRNA-Dox-SiO 2 (containing 162.5 nM MDR-1 siRNA) that encapsulated Dox at various concentrations (500, 1000, $2000 \mathrm{ng} / \mathrm{mL}$, respectively), Dox (2000 ng/ $\mathrm{mL}$ ) group, $\mathrm{NC}$ siRNA- $\mathrm{SiO}_{2}$ (containing $162.5 \mathrm{nM} \mathrm{NC}$ siRNA) and NC siRNA-Dox- $\mathrm{SiO}_{2}$ (containing $162.5 \mathrm{nM}$ NC siRNA with Dox concentration at $2000 \mathrm{ng} / \mathrm{mL}$ ). After incubation for $24 \mathrm{hrs}$, the wells were replaced with fresh culture medium and incubated for another $36 \mathrm{hrs}$. After that, the adhesive cells were digested to suspension cells and then treated with FITC annexin V reagent following the manufacturer's instructions. Finally, the cells were analyzed by flow cytometry. No treatment worked as control group. All experiments were performed in hexaplicate.
A



B

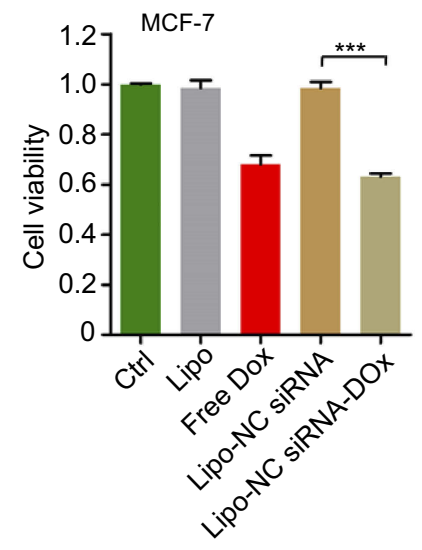

C

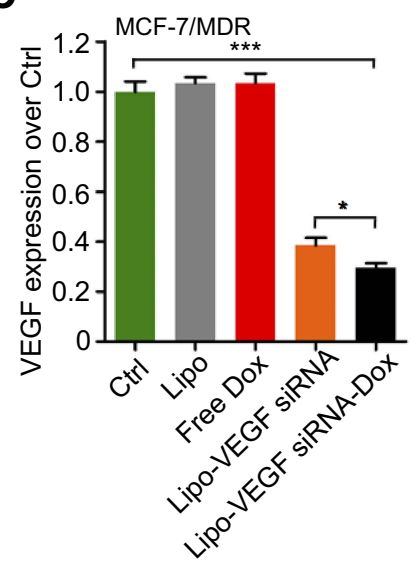

Figure SI Biological function tests of siRNA-Dox complex. (A) Cytotoxicity of MCF-7 or MCF-7/MDR cell lines in treatment of various Dox concentrations (rang from I00 to $2000 \mathrm{ng} / \mathrm{mL}$ ). (B) Cytotoxicity of MCF-7 cells treated with various formulations. Lipo, Lipofectamine ${ }^{\text {tm }} 2000$; Lipo-NC siRNA, NC siRNA loaded Lipofectamine ${ }^{\text {tm }} 2000$; Lipo-NC siRNA-Dox, NC siRNA-Dox complex loaded Lipofectamine ${ }^{\mathrm{TM}} 2000$. (C) VEGF expressions in MCF-7/MDR cells regulated by various formulations. Lipo, Lipofectamine $^{T M}$ 2000; Lipo-VEGF siRNA, VEGF siRNA loaded lipofectamine ${ }^{T M} 2000$; Lipo-VEGF siRNA-Dox, VEGF siRNA-Dox complex loaded Lipofectamine ${ }^{T M} 2000$. Data are represented as the means \pm S.D. $(* p<0.01 ; * * * p<0.0001 ; n=3)$.

Abbreviations: siRNA, small interfering RNA; Dox, doxorubicin; NC siRNA, negative control small interfering RNA; VEGF, vascular endothelial growth factor; VEGF siRNA, vascular endothelial growth factor small interfering RNA.

A

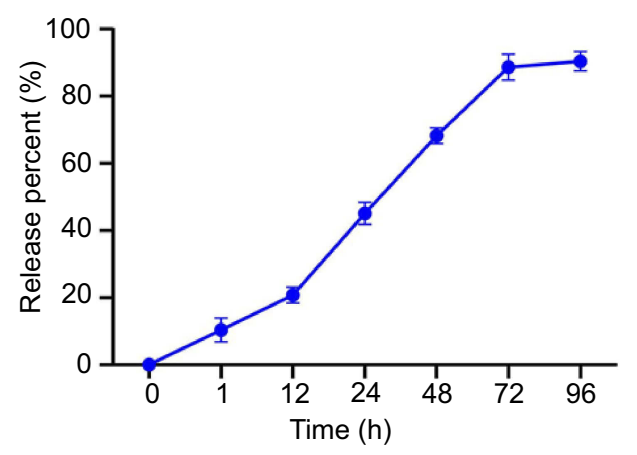

B



Figure S2 (A) siRNA release profiles of siRNA-Dox-SiO 2 nanocarrier in PBS at different time points (I, I2, 24, 48, 72 and 96 hrs). (B) Agarose gel electrophoretic analysis to evaluate the siRNA release at different time points. Lane I: I hr; Lane 2: I2 hrs; Lane 3: 24 hrs; Lane 4: 48 hrs; 5: 72 hrs; Lane 6: 96 hrs; 7: free siRNA (equivalent to the total loaded siRNA in siRNA-Dox-SiO 2 nanocarriers); 8: DNA ladder (50 bp).

Abbreviations: siRNA, small interfering RNA; Dox, doxorubicin; $\mathrm{SiO}_{2}$, silica; PBS, phosphate-buffered saline; DNA, deoxyribonucleic acid. 




Figure S3 Evaluation of endosomal escapability of FAM-NC siRNA-SiO ${ }_{2}$. Fluorescence images of MCF-7/MDR cells incubated with FAM-NC siRNA-SiO 2 vectors for 4 hrs and 24 hrs using confocal laser scanning microscopy (CLSM).

Abbreviations: NC siRNA, negative small interfering RNA; Dox, doxorubicin; $\mathrm{SiO}_{2}$, silica.

A

(a)

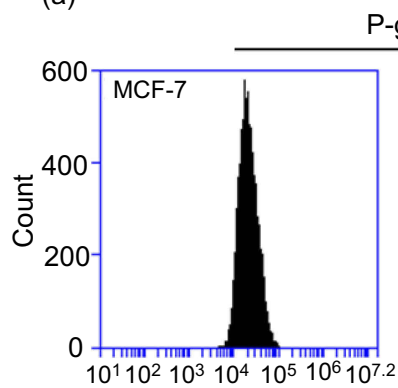

P-gp expression



B

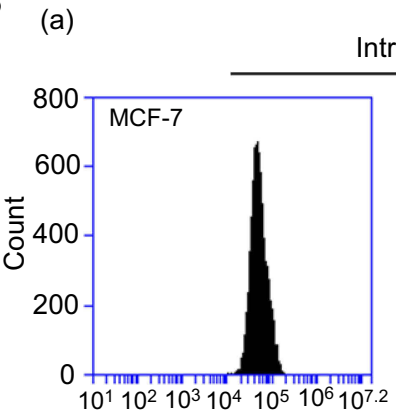

Intracellular Dox

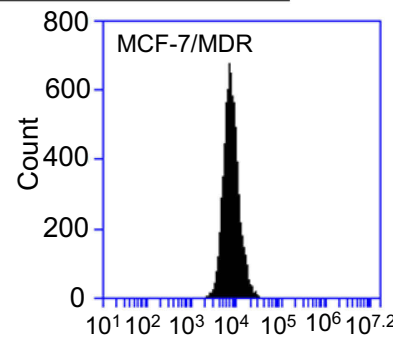

(b)

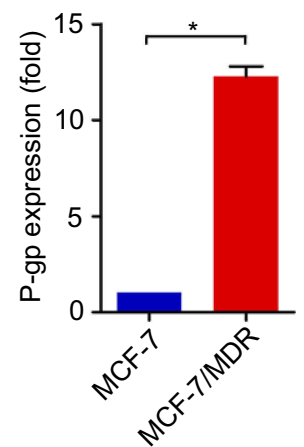

(b)

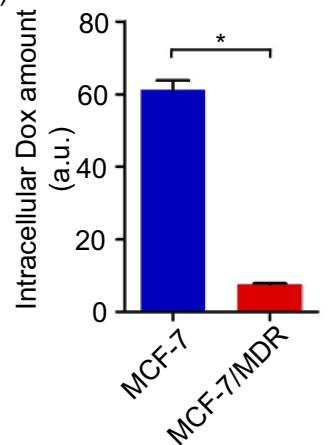

Figure S4 (A) P-gp expression determined through flow cytometry in MCF-7 and MCF-7/MDR cell lines (a). The corresponding statistics analysis (b). (B) Intercellular Dox retention measured by flow cytometry in MCF-7 and MCF-7/MDR cell lines (a). The corresponding statistics analysis (b). $\left({ }^{*} p<0.05 ; n=3\right)$. 

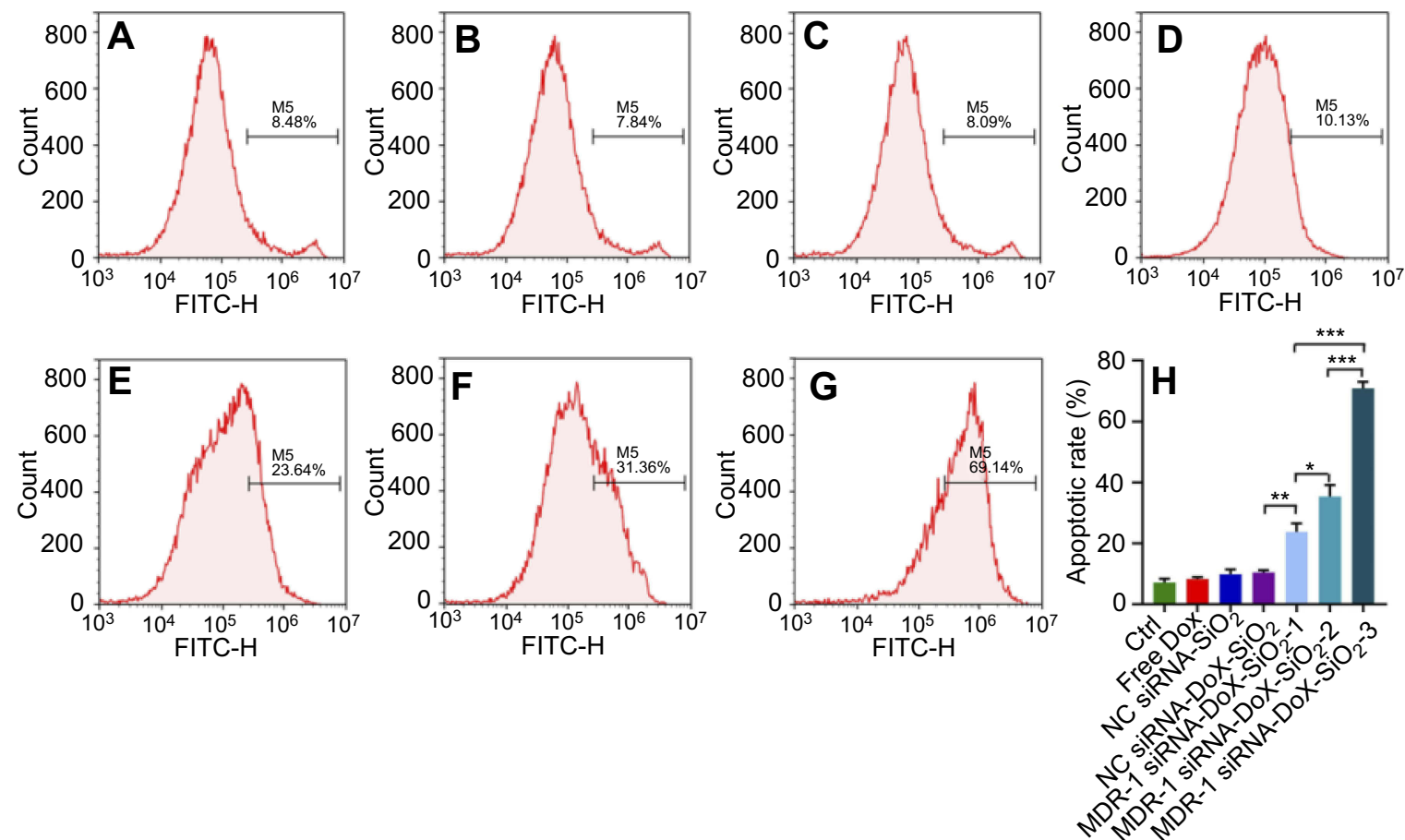

Figure S5 Evaluation of apoptosis of MDR-I siRNA-Dox-SiO 2 containing different Dox concentrations determined by flow cytometry using annexin $\mathrm{V}$ method in MCF-7/ MDR cells. (A) control, without any treatment; (B) Free dox, dox concentration of $2000 \mathrm{ng} / \mathrm{mL}$; (C) NS siRNA-SiO ${ }_{2}$; (D) NS siRNA-Dox-SiO 2 , Dox concentration of 2000 $\mathrm{ng} / \mathrm{mL}$; (E) MDR-I siRNA-Dox-SiO 2 - I, Dox concentration at $500 \mathrm{ng} / \mathrm{mL}$; (F) MDR-I siRNA-Dox-SiO 2 -2, dox concentration at I000 ng/mL; (G) MDR-I siRNA-Dox-SiO $2-3$, Dox concentration at $2000 \mathrm{ng} / \mathrm{mL} ;(\mathbf{H})$ Quantitation of apoptotic rate of MCF-7/MDR cells after treatment with different groups. All of groups contained the same siRNA value. M5\% represents apoptotic cell population\%. ${ }^{*} p<0.01 ; * * p<0.001 ; * * *<<0.000 \mathrm{I}, \mathrm{n}=3$.

Abbreviations: NC siRNA, negative small interfering RNA; Dox, doxorubicin; $\mathrm{SiO}_{2}$, silica.

\section{Publish your work in this journal}

The International Journal of Nanomedicine is an international, peerreviewed journal focusing on the application of nanotechnology in diagnostics, therapeutics, and drug delivery systems throughout the biomedical field. This journal is indexed on PubMed Central, MedLine, CAS, SciSearch ${ }^{\circledR}$, Current Contents ${ }^{\circledR} /$ Clinical Medicine,
Journal Citation Reports/Science Edition, EMBase, Scopus and the Elsevier Bibliographic databases. The manuscript management system is completely online and includes a very quick and fair peer-review system, which is all easy to use. Visit http://www.dovepress.com/ testimonials.php to read real quotes from published authors. 